\title{
The future of social media for online communities - Interview with Rudy Thurston, Chief Operating Officer at Omnifuse, Inc.
}

\begin{abstract}
Rudy Thurston
has a decade of experience developing infrastructure and software architecture to Omnifuse's clients. Before co-founding Omnifuse, Rudy served as the enterprise open systems configuration management director for the Automobile Club of Southern California, where he oversaw the source code and build automation of mission-critical business applications. Previously, Rudy owned a consulting company developing software solutions for many FORTUNE 100 companies, including Microsoft and its Windows 2000 operating system development. Rudy holds a bachelor's degree in business with an emphasis in economics from the University of Maryland and a master's degree in engineering in Applied Computer Science from the University of Southern California. A former competitive tennis player, Rudy works today with youth tennis programs to pass along his vast knowledge and experience in the sport.
\end{abstract}

Keywords: social networking, interstitial ad, social media, viral video, online community

Abstract Rudy Thurston has been developing social media infrastructure for Omnifuse for the past decade. We spoke to him recently about some of his successes in the field and his view of the future of social media for online communities.

Journal of Digital Asset Management (2008) 4, 92-100. doi:10.1057/dam.2008.11

MM: So as we start this, why don't you just start off with your name, title and an overview in terms of Omnifuse?

RT: Sure. My name is Rudy Thurston. I'm the $\mathrm{COO}$ of Omnifuse. Omnifuse is a social media marketing and technology company that started in earnest in 2003. We've been working on our social media platform for a little over seven years, now. Almost going into eight years, now.

MM: As a social media developer, this means that you develop a technical platform and license, or provide it to other companies? RT:Yes. That's one facet of our business. Our flagship product is FUSION. That's a traditional social networking application.

We also provide strategy consulting for clients who already have existing social networks, where we help them with memberships. We help them with identifying their target demographics, and inflection points of social media into their social networks, to get more excitement, or to drive more specific types of traffic to their communities.

We specialize in building communities. Whether we're using the technology that we created to build those communities, or using our community expertise to continue to build those communities.
MM: Perhaps we can go next with a broad overview in terms of key developments and trends in social networking and social media. RT: Sure.

We're a very interesting kind of company, from maybe some other social networking companies out there.

Omnifuse came about because my business partners and I had created a community around action sports - icelounge.com. We actually tested our own platform out and created our own community. We went through the whole process of seeding a community from scratch, understanding the taxonomy and searchability of community while figuring out what features and functions people needed to have to create a great interactive experience.

We come from the experience of building our own community and the technology around it.

It's interesting. Our platform is now on its fourth major version. If you think back to the days of e-commerce when people were just bolting stores on to their existing web presence; that was kind of the tactic we took originally with FUSION. It was a bolt-on community to an existing web presence.

As our product matured and we continued down the path of listening to what our 
customers really want from our technology offering - FUSION has become a very large content management system that includes usergenerated content as well as other types of managed content.

Content can be anything from a blog or form or posting a comment - a rating or review. A video file. A picture. A page.

These systems are becoming more and more tightly integrated and becoming the primary web presence for these companies. That's been the trend for FUSION - and seeing how we've moved from, "We'll make it look like yours and bolt it on," to having all aspects of web presence completely interconnected.

MM: This reminds me of an interview with Eric Schmidt of Google on the Charlie Rose show about two years ago, when he said that the eighties were all about hardware. Out of that we got Seagate and Maxtor and EMC and Compaq and HP and IBM. Apple and Dell and all those kinds of things.

By the time we got out of the 80 s, the innovation space had been all used up.

Then we got into the 90s and Eric said it was all about software. Then we had Microsoft and IBM and Oracle and Peoplesoft and Siebel and SAP. Guys like that.

By the 2000s, all the innovation space had really been used up for enterprise software. He said the first six years of the 2000s were all about internet and infrastructure. Out of that we got Amazon, Yahoo and eBay and Google and MSN and a couple of others.

But he said that as of 2006, there's never going to be another eBay and there's never going to be another Yahoo.

He said, "The future - this next wave of innovation and wealth creation and successful IPO's is going to be about small groups of people that produce and consume small chunks of information and content."

RT: Sure.

MM: As they produce and consume, at some point, they hit a critical mass. At that point, you get Skype. You get Facebook. You get MySpace. You get LinkedIn or whatever.

So Eric Schmidt was really making the case that the next big wave is going to involve social media, or media in social networks. I can only assume that you would violently agree with that. RT: Violently. Yes.
MM: Who are your clients? And how are your clients harnessing that notion of media social networks?

RT: I guess one of the easiest ones to talk about that shows the true power of the networks the Icelounge test case that I spoke about which is really the test case for our technology and our understanding of communities.

It was a hugely successful community. We created a community of roughly 50,000 skateboard enthusiasts.

MM: This was for which company? RT: This was our own test case. This was how we actually started Omnifuse. Omnifuse was started from icelounge.com, which was our skateboarder community.

MM: That still exists? IceLounge.com? RT: Yes. You can go there. It actually will forward you to IgnitionSk8.com. This community was so successful, it was a highly sought-after demographic, we ended up selling the community to a mobile action sports provider. Ignition was the name of the action sports mobile content provider.

We worked with them to create a seamless integration to their mobile content store.

It's interesting because communities are really sensitive to authenticity. So if you have something that you want to sell them, you'd better do it in a very, very precise way.

As soon as you have a sense in your community that you are just trying to "sell" to the membership, your community is done. They're not going to accept it. They lose that sense of authenticity that's so important when you're building community.

One of the things that was interesting was, in this demographic particularly - 15- to 18-year old male skaters — was very receptive to this kind of mobile content. They could have their favorite skateboard company logo as wallpaper or their favorite shoe company pictures or ring tones for their favorite rock group. Integrating the ability for members to not only consume those pieces of content, but also to rate and review them, and tell other members how much they liked or disliked this piece of content drove their mobile store to the point where we actually had to rebuild it for them, because it wasn't effective enough at managing all the content they were distributing. 
So a skateboard community of 50,000 members, in the years between 2005 and 2006, generated additional revenue by using the community to drive pay-per-use content in their mobile store.

Again, it had to be done pretty subtly. We couldn't just throw a whole bunch of ring tones and say, "Here, you guys. Buy these, now." We really did it in an integrated fashion, to show when they were looking at a group and that group was DVS. We were showing them DVSspecific content.

MM: DVS?

$\mathbf{R T}$ : Yes. DVS is a shoe company. It's a hardcoreskater shoe company. We were showing DVSrelated content to the members.

MM: Did you generate the DVS content? Or was that coming from DVS?

RT: It was Ignition's business model to acquire the sole licenses from many of the action sports companies for mobile content. So they were the licensees of all of that content.

We provided the software mechanism that allowed the contextual serving up of the content meaningful to the user as they were navigating through the taxonomy of the site.

MM: Before you go there, Rudy — it seems to me that in creating a content commerce opportunity within a community, it means that the content has to really be woven into the fabric of that community.

RT: Absolutely. Like I said, one of the things that was interesting in our case study of icelounge.com - the first time we turned banner ads on, on the site, we got completely killed. We were getting death threats. It was just an absolute failure.

Here we were thinking, "Okay. We really want to start to monetize this community." We'll just throw some banner ads at it." We worked with Tribal Fusion and integrated their ad system into our ad system.

MM: That would be an ad-serving system? RT:Yes. Into our community software. It was great. It worked just perfectly. You talk about nailing out of the box, the first time. Then the users just revolted. They just absolutely hated it.

"Why are you selling me underarm deodorant?" We took it down within one day. It was that bad.

MM: If I understand you right, when you plugged in an ad network - in this case, it was
Tribal Fusion - but that network then goes out and finds advertisers to generate ads that then get dynamically served into your site based on some metadata profile of the user. RT: Sure.

MM: Your users came back and said, "This isn't part of my tribe."

RT: Right. This is so far away from what I want to be seeing on my community. If you don't get it out of here immediately, we're going to go somewhere else.

MM: So this kind of gets to a deeper - almost social - issue. Which is to say that the community... Their social identity and who they consider themselves to be had now included membership. Not just membership in the community, but almost a companyownership of it.

RT: Absolutely. A very big and important part of establishing a community is that identification. The personalization of it at every level. It's the most important part of building that vibrant community.

MM: There are probably two dimensions of it. One is relevant content - relative to the tribe and the activity of the tribe. Then the other dimension of that is personalization. Is that a fair characterization?

RT: I would think that's a very fair characterization.

Let me complete my ad story, because the story gets a lot better. We came back after about six months, licking our wounds from that experience. We came back to the community this specific skateboard community. This time we came back with ads that were little video vignettes provided by skateboard shop owners showing their products. These videos were primarily skaters that the shop sponsored demonstrating products they sold. All things are action-sports-centric.

We launched that, and they loved it. They thought the content was so relative. They didn't mind that it looked like a commercial. They just really enjoyed the content.

Again, a huge success. Most of the skate shop owners that bought these ads were able to demonstrate real bottom-line results from the ads displayed on the community. So much so, that we doubled the revenue that we were generating from the interstitial ads in that sixmonth period of time. 
MM: Would you explain just for a moment what you mean by an, "interstitial" ad?

RT: Yes. An interstitial ad is one that's served up prior to viewing some sort of content on the site. If you were to look at ignitionsk8.com site right now and were to click on a video before that video pops up in the player, you'll be served up an interstitial ad.

MM: Is that sometimes called a pre-roll?

RT: It could be a pre-roll. Yes. In our case, we're using the term "interstitial" just because of the way we sell the ad to a company. This is all in the past. There's a little bit different philosophy on the site, now.

But when we were selling the interstitial ads, we were using that term very specifically. Because we wanted to make a differentiation between a standard pre-roll and an interstitial being something that was more contextual.

MM: Got it. So it was part of the story. RT:Yes.

So the first time, we failed - and the second time, we were very successful. That led to us selling this site to the mobile content provider, and then working with them to create four additional verticals for all the specific action sports. They're using our technology platform for that.

MM: On the second time out - when you went to vendors and/or shops that were part of the community — for the most part, we're talking about... I won't call them "amateur," but we'll definitely call the "low-production-value videos. They kind of had the home-movie, home-video flavor to it.

RT: Absolutely. One of the reasons why we picked skateboarding as our primary targets is that skateboarders are natural videographers. They're always out there taking videos of their friends doing tricks. They're just natural-born videographers. They want to see how everybody else does a particular trick.

They're going to tape themselves doing it. They're going to review it and watch it. We needed to understand the dynamic of how rich media content was consumed and successfully embedded in the community.

Also, the technological challenges of uploading video and converting video to Flash, and doing all that good stuff — which we'll get into later on. MM: That reminds me of a conversation I had with a VP of research at MTV in Europe. He called these things, "Games of Cool." It was all a matter of how well you played this particular game of cool.

Again, in your skateboarder community, you've got one dimension that is just plain skill. Quick, cool moves. The other one is, of course, what you look like in terms of both the hardware and the shoes, the look, and "How do I make myself look like that?" Therefore, a member of that community.

RT: Right.

MM: There are really two dimensions. One's skill and the other one's basically "cool" identity. That lends itself perfectly to video.

RT: Yes. It does. Those two dimensions are identifiable characteristics for commonality within communities.

MM: One of the things that we've understood now from the cognitive research and cognitive science of community building is that almost always, it entails communication, interaction and collaboration among peers. There's no kind of authority by which to intimidate people.

It develops a kind of common vocabulary and a common way of relating. Thereby reinforcing a ritualized way of communicating, interacting and collaborating. Does that make sense?

RT: I agree with that. Yes.

MM: Would that include blogs and wikis? Take me through some of the tools that a client might provide a sponsor.

RT:Yes. Blogs, forms and groups are the three primary places where they can interact.

MM: For the context of this interview, could you explain the difference between a forum and a group?

Sure. A forum is what we call a site with a monitored topic. We'll give special permissions to actually moderate a forum. They'll create the forum and the topics for the forum. Then members will interact with the topics, the descriptions and the conversation about that topic.

MM: Essentially, a moderated special-interest group.

RT:Yes. And a group is really more memberdriven. A member can create a group around a specific topic, and they can be the center or focal point of that group. It's more free form, and not as shaped of a conversation as a moderated forum.

MM: The content of a group is on the site? Or is it circulated by e-mail? 
RT: It's all on the site. Yes. It's contained within the site. And groups can be private so you have to have special invitation to be a member of that group. Forums are always public.

MM: How else would you see that downline affiliate relationship working? Obviously, that would accelerate the propagation of another client for you. Right?

RT: Sure. Again, one of our key strategy plays is to help our clients determine and look at all of the different ways that they can do that.

Specifically, other people who are vested in the content that you're providing. And helping us at the level of providing that content that's going to drive the community by putting them in the place where they can provide the content, themselves. Or link into the content, and embed the content within the community.

The other really great thing about a platform is that we can read in digg, del.icio.us, RSS from many different places and allow the community to consume those, as well. That gives them the ability to repurpose content.

MM: Now, as the digg or del.icio.us community starts doing its social bookmarking around some of your content they're just basically out there, and you're not part of any kind of revenue share. Is that right?

RT: That's right.

But what makes the more compelling story is... If someone were marking a specific type of content, we know what kind of content they were bookmarking. We can go find it for them.

Specifically, what we try to do is work with our clients, to identify the type of social media content - usually a social bookmarking, to identify the media categories that these people are trying to consume - and provide that for them, dynamically.

MM: So in a digg or del.icio.us group, you add additional tags for them?

RT: Yes. We just catalogue the tags ourselves, too. We have to pass the information on anyway. So we just capture it and we make sure we know what they're looking for. In that case, we can actually be proactive in finding content for them that they may be specifically interested in.

We're really trying to drive the content that's specific to the content that our clients want their social media and networking people looking at. So they're shaping it more around their brand and product offering. Specifically, a community that's built around Yamaha Outdoors, that's using a version or a platform that allows members to create social things like digg and del.icio.us. Using social bookmarking to create bookmarks around sports fishermen - different types of sports fishermen. Yahoo's infinitely interested in that, because they sponsor 16 of the top bass pros. We're trying to drive their bass pro content, because they're already offering it up and they're already invested in producing that content. We're trying to demonstrate the ability to get more people to see that content that they've already created.

MM: That Yamaha content that they generated live at Yahoo?

RT: No. It lives within the community that we created for them.

But it's bookmarked, and it's part of digg and del.icio.us. So other people can find it from many different sources. What we're doing is using those captured bookmarks to push more of their specifics.

So if somebody were on our community looking for comments about a particular flywheel for a particular rod, we could send them content specifically from one of the bass pro sponsors that Yamaha Outdoors is sponsoring. Obviously, they're going to be promoting the flywheel from the Yamaha line. MM: This clearly would be a good segue into using more like user-generated video and professionally generated video.

Yes.

MM: As I understand it, you had — within Omnifuse - a media-production group — and you've begun to look for ways of outsourcing parts of that video-processing.

RT: Absolutely.

In the earlier versions of our platform, using some of the industry-standard tools out there, we created a mechanism to take video and convert it on the fly to flash. But it was just a real nightmare of a support scenario, where we were always having to keep the codices up-todate, and go through the whole process of maintaining the software updates that creates the video-processing engine.

It just became a little bit overwhelming. We're not specifically video-processing engineers, although we have some experience in it. That's not what we do full-time. We're socialnetworking guys. 
We immediately started trying to identify partners that could help us with the video processing, in particular. Especially videoprocessing to mobile, video-processing to Flash - video processing to all of the particular elements for that consumable media part that we were looking for.

MM: What criteria did you use in selecting a video service provider?

RT: Really, there were two primary things. The first thing we were looking for was a tried-andtested video-processing engine that was maintained by that specific third party. Meaning they were vested in making sure the codices were always up-to-date. And making sure that the software stayed current with the technology that was out there.

The second thing was somebody who had a world-class delivery network that could deliver this content in an extremely reliable fashion anywhere in the world.

MM: So now we're talking about contentdelivery systems such as Akamai or one of the other guys. What we're talking about is the ability to push large pieces of content out to the edge of the internet.

RT: Right.

MM: Across several thousand different servers.

So that it wasn't all having to serve from one central server on your site, but from stuff that was already cached in the network.

RT: Absolutely.

One of the other painful lessons that we learned was as follows - we always provide an embed tag and a URL tag for every movie that we created - every Flash file that we created - so that members could put them on different profiles and different social networks.

When you get one or two that get really, really popular, you find the holes in your infrastructure very quickly. We've painfully found that out from our ISP when we had two of our videos hit YouTube's top 10, and they started to generate 250,000 hits a day. It was quite overwhelming, at first.

MM: What were some of the behavioral or physical effects of having a YouTube hit on your business and infrastructure?

RT: The primary one was the bandwidth. We were consuming a tremendous amount of bandwidth.
Our bill went up, first. That wasn't so bad, because we actually had our own dedicated pipe. Our own dedicated bandwidth, coming in. We actually host all of our equipment at a collocated facility, because it's backed up and redundant and all that good stuff.

Yes. Our bill went up because our spike traffic went way up. But that wasn't the most impact. The most impact was the degradation in overall performance of our network sites. So we learned the hard way about filtering, sheltering web-farms and all kinds of stuff.

We had some of that in place, before. But definitely not to the scale that we have it now. MM: As a function of having a video-processing engine - a proven, video-processing engine that was able to keep provisioning out content to all of the various players... whatever version they were on... And then this content-delivery network... If you had a big hit, that allowed you to buy bandwidth on-demand, almost. Essentially, all of the traffic was on the edge network as opposed to coming out of your server.

RT: Absolutely.

We went through that about a month ago, when three of the Skateboard videos on the ignition site went to the top 10 on YouTube. Our applications experienced no significant issues or lag time.

MM: So other than a mature, maintained video engine and a world-class distribution network, does any other criteria go into selecting a video service provider?

RT: One of the more subtle things that we were looking for - we were looking for a partner that built their technology on the same technology that we built our platform on. Microsoft.net and that enterprise-scale architecture. That was another reason for us choosing (on stream). They had built their technology on the same technology that we were working with.

MM: Therefore you got a known devil as opposed to an unknown devil, and you knew what you were dealing with, to be able to integrate.

RT: Absolutely.

The secondary part of that was, we didn't want to be the first person trying to integrate their solutions. We wanted somebody who'd been integrated and had done this UGV 
integration before, and been successful at it. Another key place for us where we selected OnStream. Because they'd been doing this for a long time. They have a very mature web-services architecture for us to call into and receive data back from.

MM: What were some of the steps, in terms of the predeployment? I understand you're still doing production pilots or doing QA testing.

What are some of the things - if somebody is reading or hearing this... If somebody's got a social network or corporate website, what are some of the things that they should put in place before they start integrating either social media - broadly spoken and broadly defined, and/or specifically as user-generated video - vis-à-vis a video services provider?

RT: The first thing is definitely a good partner to work with. Corporations definitely don't. I can't recommend strongly enough that a corporation definitely finds a partner for doing this with them. There are so many pitfalls in the user-generated video. Adding those pieces brings great, great additional ways of getting content. Getting people excited. Rich media is just great for interactivity and stickiness. People love it. They like to consume that stuff.

But you want to have a very good partner, who knows the ins and outs of trading that content and distributing that content. There are so many places where it can be overwhelming and can fail quickly because of all of the different aspects of it. Finding that good partner is definitely the primary key to success.

Then just really understanding what type of rich media content you're either trying to acquire through user-generated videos - or that you're trying to produce and put out there to the web.

Those things - again — especially when you're in a production facet, where you're trying to create this content... Do you really need a Madison Avenue ad firm? And a Steven Spielberg production video? When it's going over the web and it's going to be consumed and at maximum 20-grains per second, and not HD?

The way that it's going to be consumed should have a direct reflection on what production level it really requires for you to put it on there. When you're looking at that rich media content, production quality isn't the primary driver of why people are consuming it. It's the content, itself.

So it's not necessary to have the bells and whistles of a full-blown production. It's more about the content and the type of content that's being distributed to people. Some of the most successful videos on the web are shot with a cell phone camera and a person speaking.

MM: And you got to it earlier in the interview when you talked about how authenticity trumps everything.

RT: Yes.

MM: If it really is user-generated content, almost by definition, of course - unless you're talking to a group of ad directors - creative directors - almost by definition, user-generated content is amateur.

RT: Yes. Absolutely. Even if you want to look at some of the brand name pieces. Like the Doritos commercial that was shot by the kid. He created a very simple, low-production Doritos commercial. One of the most successful Doritos ads ever. It was created by somebody who loved Doritos.

MM: Do you see that as another development where you're going to have user-generated brand stories? I won't call them promotions, but they're almost like testimonials. Yet they're also homages to what a great product or service it is.

Yes. We're definitely seeing a lot of people trying to do that. The problem is, again, the authenticity of it - and how authentic you can make it.

Having the tools in place to capture it when it happens is going to be key. But it still has to have that spontaneity to it. That's a hard one to answer, because I really know so many marketing companies that have tried to come up with that piece, and identify that piece. It's just the spontaneity of it.

If you have the tools in place to capture it.. MM:You've got another dimension, here. Not only is it authentic, but there's a poetry. There's a spontaneity and a freshness to it.

RT:Yes. Again, that leads back to the authenticity of it.

MM: It could be authentic, but it could just be yesterday's news.

RT: Sure. Good point.

MM: As we wrap up our time here, can you share with us some more forward-looking comments or ideas about the use of widgets and 
some of these other sorts of things that we read about in these little applets or mash-up kind of applications that you see at FaceBook? And how that ties into some of the things that you guys are doing?

\section{RT: Absolutely.}

We work with a company very closely. A company called iLike. There're a digital, online music company.

What ended up happening was, they used their FaceBook app to add a little widget into the FaceBook profile that. And a lot of people who already had profiles on iLike... To bring their music over into the FaceBook application. So successful, they were signing up like a half million members a month. It just blew up. It was absolutely unbelievable how successful they were capable of, in bringing new members to their site by just adding a FaceBook extension to their application.

MM: So there I am in my FaceBook profile, and underneath, I've got the little interesting factoids about my stuff, and what groups I'm a part of. In that profile, I've now added a little visual image of what, as it relates to iLike?

RT: Right. What happens is, you have a series of applications that you can add to your profile. You go to their little list, and you find the iLike application, and you add that to your profile. That gives a little popup - a little window - right there. You can log into your iLike profile, and your iLike profile then sucks in your iLike music, right into your FaceBook profile.

Then you can recommend your music to other FaceBook members. You can recommend FaceBook members to sign up for an iLike profile.

MM: The kind of data that's moving across there would be like the artist and the song and things like that?

Exactly. It's really simple. They're just links to the iLike site.

MM: Right.

RT: They're basically getting members to distribute links all over the web through the FaceBook application to their content. That's what's driving a tremendous amount of their membership building right now. It's really coming through this tremendous distribution of their content - through the FaceBook application.
What we're seeing, though — and our idea of the future of social media as a whole is that... We're getting very close to the saturation point of having a framework that can consume and create and consume profiles from all kinds of different social networks.

The FaceBook application doesn't just allow you to read into it. It also allows you to read from it, as well.

If you have a FaceBook profile and you have a MySpace profile, and you have an iLike profile and all these other profiles, we believe that the next iteration of this will be a mash-up or an integrator of all of these profiles, into one social media profile. One big profile.

MM: So now I've got all of my social media positions integrated almost to a dashboard. RT: Absolutely. That's exactly right. A dashboard is exactly how we describe it in our technology meetings.

MM: And all this dashboard is really doing is syndicating in content streams.

I would imagine that in some cases, you'd have a window into MySpace or into these virtual reality things or metaverse things - like Second Life. Or maybe one of my massive multi-user online game things.

RT: Absolutely.

Specifically, our market space is comprised of Fortune 1,000 companies. We see it as the ability to expose these profiles that are built within MySpace, FaceBook - those are the profiles that you're really looking for, when we're reading in-profile information from these other networks.

We're hoping that people adopt those as the standard. Then instead of having to type all of that in, there's actually a company out there trying to create a unique ID for everybody that is your personality and your piece that floats around the internet.

OpenID. Yes. OpenID's whole idea was that everybody would create these profiles in OpenID. That one profile would then be the profile that FaceBook uses - my Space uses all these other people consume that profile and can maintain this one profile for the entire web. MM: Are there progressive levels of disclosure? RT: Yes. It can set privacy settings and all that good stuff. The problem is that nobody wants to share their data. Everybody wants to own their data. So that idea doesn't work. 
But what we've seen is that specifically in the FaceBook and MySpace world - these profiles have primarily accepted de facto standards. So we're saying, "Okay. Let's use those. Give us a nice rich API to read them in from. Keep your profile there and manage it all there. But let's bring some of that data into this profile that we're creating for you, here. We'll tie them together so you can manage all the data in one place. But we're going to make it visible, too."

You're essentially making it visible to multiple communities.

MM:You know, this sounds like the metadirectory of Napster.

RT:Yes. Very similar. The idea really comes from that type of thing. And I have to wrap it up, here. MM: I want to thank you so much, Rudy. 